\title{
BE ATTRACTIVE ON TINDER - HOW TO CREATE YOUR IMAGE THROUGH ONLINE DATING APP
}

\author{
Atiya Isfahani \\ The London School of Public Relation \\ atiyaisfahani@yahoo.com
}

\begin{abstract}
Human interactions are being communicated by means of electronic, Internet-based Medias. This research is about representation differ in presentation on online dating applications. This study is aimed at understanding how images are used as a means of creating an identity, specifically through Tinder. Self-presentation is divided into two parts: the front region and the back region. The front region is the area where a person displays a self-presentation that he/she wants to show the audience or user in this context in the picture. Front region consists of setting, appearance, and manner that are related to each other. In the back region, the appearance is a visual appearance that is not displayed or any activity performed. That will create impression management in Tinder which create personal branding. In this study qualitative method are used to answer the research questions. The process of research involves emerging questions and procedures, data typically collected in the participant's setting, data analysis inductively building from particulars to general themes, and the researcher making interpretations of the meaning of the data. The results showed that starting from self-presentation, every participant have their own style to build their own personal branding to make him/her unique among all the other tinder user. This allows them to stand out. The implication of this research is the need for management of personal branding for every individual involved because personal branding is really important as a form of self-presentation in order to compete in relationship or business.
\end{abstract}

Keywords: online dating app, self-presentation, tinder

\section{INTRODUCTION}

Invention in communication technology such as mobile phones and the internet, making humans increasingly improve the way of communication. Various kinds of media to communicate was present to facilitate human interaction (Kallis, 2017). Along with the development of the times, internet technology has become a necessity for the community, this is what gave birth to social media. Social media is an online medium, mean that media that only exists by using the internet where its users can pour ideas, express themselves, and use according to their needs (Kallis, 2017). The presence of social media makes it easy for humans to communicate and socialize. Dating is a market where people are looking for the best possible partner. The most important impact of the transformation to online dating was the decrease in transaction cost. Finding a partner before the Internet was expensive and the market was inefficient. There could be people searching for partners, but it was difficult to find one. With online dating platforms, it is easy to find a potential partner, who might also be interested in you. The use of dating search application is currently busy used by the people of Indonesia. This is evidenced by the number of dating search applications such as bee talk, grindr, meowchat, okcupid, tinder and many others. Dating search sites are believed to provide a solution to the speed and accuracy of the arrival of a mate for its users.

This phenomenon makes a shift in meaning to dating where in the past dating will be done by couples who have been through introductory stages, approaches, new explorations followed by a date. But today the stage is shortened to an introduction through the application search mate followers, then meet for a date (Fridha \& Octavianti, 2017). With online dating is so easily accessible, it is changing the way people present themselves and it is changing the way they interact with others. Tinder has 
roughly 50 million users on the application and 1.8 million premium users, users who pay monthly to use more features of the application (unlimited swiping, rewinding swipes, and the ability to change your location and see other users from around the world) (Weller, 2017).

Understanding the life cycle of a relationship formed via Tinder can provide important data on the shifts in traditional ways in which users form and disengage in a relationship, which has implications on self-esteem, happiness, and emotional and physical well-being. Online dating applications are location based mobile applications that offer people the chance to communicate easily about meeting up, flirting, chatting, and getting romantically involved with other people in their general proximity. Specifically, these applications are available on smart phones, not standard cell phones. The motivations one has for the using online dating applications instead of alternate forms of dating vary and quite often differ dramatically. Factor that caused online dating's fast pace growth was digital photography becoming readily available. Instead of reading simplistic profiles people could now put a face to a name. Sometimes, this even involved multiple pictures, but realistically what this did was create a space where people could use more creativity and deception. People could create this digital self that made them feel good about themselves and attract a different audience (Kennedy, 2010). Eventually, online dating progressed in to online dating applications: location based dating applications accessible on your mobile device, which are less complicated than standard online dating on a computer.

Self-presentation is ubiquitous in social life: individuals try to control or guide others' impressions by manipulating setting, appearance and behavior (Goffman 1959).In view of the above, the purpose of this thesis is to investigate and analyze the role of images in the process of personal branding through Tinder. The aim is to fill the theoretical gap in social media concerning the use of images in personal branding. By highlighting foreground the role of image making in this contemporary culture. In doing so this study examines the dynamic way of communicating a person's identity and self. The approach for this research aims to add an academic understanding to the relationship between social media, personal branding and images. This approach attempts to give the authors a way of conceptualizing the role of images.

\section{METHOD}

In this study qualitative method are used to answer the research questions which means that data is collected by the writer by interpreting qualitatively. According to (Creswell, 2013)Qualitative research is an approach for exploring and understanding the meaning individuals or groups to a social or human problem aims to investigate and comprehend phenomenon within individuals or groups assign to social problem. The process of research involves emerging questions and procedures, data typically collected in the participant's setting, data analysis inductively building from particulars to general themes, and the researcher making interpretations of the meaning of the data (Creswell, 2013). The appearance of questions and procedures, then the data is provided through participants, and then the data analysis is formed from the details to common view and the data is used for the meaning interpretations of the data.The informant or key informant is the whole subject of the research which has a different role in the implementation of a study. Resources can be the key that facilitates access to research through their social networks are mainly in the early stages of the research and also are key to providing important insights for researchers. Understanding from resource persons has a big role for researchers because the resource person has a very wide knowledge through their seniority or have a special role in the research (Bloor \& Wood, 2006, p.109).

In this study, researchers will interview some users of Tinder not based on gender (5 person age 22-27). This interview aims to obtain complete data from both parties, both internal and external so that researchers can perform analysis and interpretation of research on self-presentation. This study is aimed at understanding how images are used as a means of creating an identity, specifically through Tinder. The sampling has also been done in a non-representative way and the subjects that participated make up a rather homogenous group. They are all rather young, well educated, come from a rather similar social background and from the same geographic area. Because of this the results and conclusions of this study can only be applied to Tinder and not to other social media platforms It should also be noted that the majority of the population of the world is still not using Tinder even though the number is growing. Tinder is in this study described as a possible tool for creating an identity. 


\section{RESULT AND DISCUSSION}

This research offers insight into how people use mobile dating to create their image. It also examines of new media technologies in relation to design and user behaviors. Furthermore, as smart phones and mobile applications continue to have big impact in daily lives, investigating the implications of a new media contexts will add to the growing body of literature dedicated to human interaction. The findings of this research suggests that Tinder use is mainly personal. First question asked why people use Tinder. There were no compelling averages that emerged from this question, but it appears people generally enjoy using Tinder only for fun and networking. There is a possibility that people may be using Tinder for broader social purposes, such as meeting new friends or business connections in the area. But if this is true, which asked if using Tinder to meet new people was easier than going to bars or social events, would not be accurate. People could create this digital self that made them feel good about themselves and attract a different audience

Research exploring how romantic relationships develop on the Internet has found that some people are more comfortable talking online before meeting face to face. This shows that people are just as relaxed talking to Tinder matches face to face compared with online environments. It seems the stigma once associated with online dating is no longer apparent, at least not for younger generations. Users do not feel online dating is for desperate people who are incapable of finding romance. With more social activities being conducted online and the number of Internet-accessible media applications available on smart phones, this result is not alarming. Research has shown the more tasks a person completes on the Internet, the more likely they are to participate in other online activities. How people evaluate Tinder profiles.

The questions, which asked if users look for a specific type of user on Tinder and if they only evaluate physical appearance when deciding to swipe right. Most of them prefer to show their profile picture that suit to their personality wit hoping that can find a match that also similar. For example upload a picture with nature background to expect someone who love adventure will also match. To engage in impression construction when deciding which pictures and text to include in your profile. The lower the online daters' attractiveness, the more likely they were to enhance their profile photographs and lie about things like their height, weight, and age. Yet, deceptions are rarely extreme, especially in an environment geared toward potential romance. Desired impression is one's perception of what the audience values.

The launch of Tinder's new "right swipe" limiter, investigated if people "Like" all Tinder users to boost self-esteem levels. This findings, demonstrating that people are generally selective when it comes to picking matches in regards to location-based capacities, users seemed to be somewhat attracted to Tinder because they can meet with someone immediately after chatting. Since the majority of participants fell within the 18-24 age range, this result found that younger generations to be more attracted to speed dating compared with older adults. As correlation does not imply causation, there is no statistical way to determine if the design of Tinder directly impacts its application. In regard to interactivity, users mostly strongly disagreed with question which asked if users swipe right for all Tinder profiles. The interactivity affordance allows the user to make real-time changes to the medium by swiping, Dating sites usually involve online profiles that offer users a face to the virtual world. Using $\mathrm{CMC}$ to meet potential partners presents new challenges in regard to self-presentation and selfdisclosure behaviors clicking and personally interacting with the mobile application.

The modality affordance addresses the self-presentation that people receive from using different multimedia elements, like photo and texts. It doesn't seem that users chat too extensively on Tinder. This could explain why conversations on Tinder often end quickly with users either deciding to meet in person shortly after matching or discontinuing rapport all together. As a mobile application that utilizes Facebook, question asked if checking for Tinder notifications has become a part of a user's daily social media routine. This could imply that people use Tinder with the intention of meeting someone new outside their social network. Connecting with romantic relationships online, (Hancock \& Toma , 2009) expand upon this notion by stating that online daters could use the nature of the Internet to their full advantage by enhancing their physical features in photographs because physical attractiveness is a 
quality that many look for in a mate. Since smart phones are widely used and grant instant Internet access, people are generally more accepting of using dating websites and/or applications. The results showed that starting from self-presentation, every participant have their own style to build their own personal branding to make him/her unique among all the other tinder user. This allows them to stand out.

\section{CONCLUSION}

Self-presentation described above is values self from Tinder users which was later developed into personal branding. Based on the comparison that has been done by researchers, researchers found differences from one user compared with the other is generally similar, where this is one of the elements forming personal branding is distinctive or distinctive. Furthermore, the uniqueness possessed by creating their profile picture in maintaining their image on social media. This piece of information about a partner (physical attractiveness) might actually be a great starting point research demonstrates that people can make pretty accurate judgments about a stranger's personality attributes (e.g., how introverted/extroverted they are) after merely viewing his or her photo. These judgments may be even more accurate when viewing a potential partner in real life, where appearance-based information is more spontaneous and dynamic (e.g., constantly-changing, reactive nonverbal cues such as postures, eye contact, and facial expressions). The fact that other information about potential matches is not present on Tinder may actually be a good thing as well. The implication of this research is the need for management of personal branding for every individual involved because personal branding is really important as a form of self-presentation in order to compete in relationship or business.

\section{REFERENCES}

Creswell, J. W. (2013). Qualitative inquiry \& research design: choosing among the five approaches. California: Sage Publications.

Fridha, M., \& Octavianti, M. (2017). Konstruksi Makna Kencan Di Situs Pencarian Jodoh Tinder (Studi Fenomenologi Pada Pria Pengguna Tinder Di Jakarta). Universitas Padjadjaran.

Goffman, E. (1959). The Presentation of Self in Everday Life. Edinburg: Random House. Hancock, J., \& Toma, C. (2009). Putting Your Best Face Forward: The Accuracy of Online Dating Photographs. Retrieved from https://onlinelibrary.wiley.com/doi/abs/10.1111/j.14602466.2009.01420.x

Kallis, R. (2017). Swipe Left or Right but What Happens for the Rest of the Night? A Qualitative Approach to Understanding the Life Cycle of Tinder Relationships. Theses and Dissertations (All).

Lehmiller, J., \& Ioerger, M. (2014). ocial Networking Smartphone Applications and Sexual Health Outcomes among Men Who Have Sex with Men. Department of Psychology, Harvard University.

McCord, A. (2017). Playing hard to get: Atraction, uncertainty and tinder. Western Carolina University.

Smith, A., \& Duggan , M. (2014). Online Dating \& Relationships. Pew Research Center. http://www.pewinternet.org/files/2014/01/Social_Networking_2013.pdf.

Weller, C. (2017). eHarmony is gearing up for a battle to win back millenials from. Retrieved from businessinsider: http://www.businessinsider.com/eharmony-win 